\title{
Theoretical analysis of the energy efficiency \\ of the filtration drying at the high pressure
}

\author{
$\underline{\text { Volodymyr Potapov }}^{1}$, Oleh Hrytsenko ${ }^{2}$
}

1. Department of Refrigeration, Commercial Equipment and Applied Mechanics, Kharkiv State University of Food Technology and Trade, UKRAINE, Kharkiv, Klochkivska St, 333, E-mail: potapov@bigmir.net

2. Department of Refrigeration, Commercial Equipment and Applied Mechanics, Kharkiv State University of Food

Technology and Trade, UKRAINE, Kharkiv, Klochkivska St, 333, E-mail: oleg01011989gr@i.ua

The estimates of energy consumption were performed for two methods of drying: filtration drying at the normal pressure and filtration drying at the high pressure. It is shown that the energy consumption for filtration drying at the normal pressure is higher than in the same drying mode at high pressure.

Keywords - drying, filtration drying, energy consumption, high pressure, compressor.

\section{Introduction}

In modern conditions, the problem of energy saving in production and economic activity is especially urgent because of the fast rise in prices of energy resources. One of the most energy expensive processes of the food industry is the process of drying. According to T.Kudra [1] the drying process takes $25 \%$ of national energy consumption in industrialized countries, and in the food and processing industry it takes to $30 \%$. In the context of high cost of energy even $1 \%$ of savings in energy consumption brings significant economic results. The average coefficient of efficiency of convective dryers is $12-80 \%$ with most of the losses is accounted for the exhaust drying agent (40\%). In this connection the issues of energy savings are solved in two main ways: the development of new methods of drying and the development of new technological methods of the dehydration process.

\section{Materials and methods.}

The aim of study is ground of the possibility of increasing of energy efficiency of the drying process under the influence of the of high pressure in filtration drying.. According to proposed method of drying [2], wet crushed material is placed in a sealed eveporation module (EM) where overpressure created by an external compressor. In the result of compression of air in the compressor is heated to the required temperature. When air filtering through wet porous material is fully saturated to the state of condensation of steam and then under excess pressure derives from EM. Dried zone is gradually moving from input to output EM. This drying agent completely using its drying capacity, cooled closely to ambient temperature as a result of displacement of steam fluid mixture from porous structure. As a result is absent losses of heat from the drying agent, because, as indicated above, this is the main reason for the low efficiency of convective dryers. In this method the drying heater and fan functions combined in one device - compressor, eliminating additional energy to move the drying agent as in convective dryer.

\section{Results and Discussion}

We shall considered two dryers - filtration drying at the normal pressure and filtration drying at the high pressure, which is working at the same mode when drying agent completely saturated with moisture to relative humidity $\varphi_{2}=1$ at the output of the dryer. Although, for convective drying of such mode in practice is not used (usually $\varphi_{2}=0,5-0,6$ ), but humidity $\varphi_{2}=1$ at the output of the dryer is the theoretical limit of efficiency of convective drying (at normal atmospheric pressure). For filtration drying at high pressure, as indicated above, this mode is the basic operating mode. Productivity on evaporated moisture for both dryers taken the same as the temperature of the drying agent. 
As you know, the temperature of the adiabatic compression process in the compressor is connected to the pressure thus

$$
t_{1}=\left(t_{0}+273\right)\left(\frac{p_{1}}{p_{0}}\right)^{\frac{\gamma-1}{\gamma}}-273
$$

where $t_{0}, t_{1}$ - temperature at the inlet and outlet of the compressor ${ }^{\circ} \mathrm{C}$;

$p_{0}, p_{1}$ - pressure at the inlet and outlet of the compressor, $\mathrm{Pa}$;

$\gamma$ - adiabatic index of air $(\gamma=1,4)$.

Calculation of this formula shows that with increasing pressure from $0.15 \mathrm{MPa}$ to $4 \mathrm{MPa}$ temperature at the outlet of the compressor increases from $60^{\circ} \mathrm{C}$ to $160^{\circ} \mathrm{C}$ (actually in compressor the process is polytropic and $\gamma<1.4$ respectively outlet temperature slightly less).

The calculations assumed that for convective drying heater should heat the air to a temperature $t_{1}$ at normal atmospheric pressure. In filtration drying temperature is provided by compression in the compressor to the appropriate pressure $p_{1}$. To calculate the parameters of humid air we used classical equation [3]. The air parametrs at the outlet of the dryer was determined for isenthalpic drying process.

We obtained formulas total specific energy consumption for the filtration drying process at normal pressure and high pressure.

Total specific energy consumption for the filtration drying process at normal pressure is equal to the sum of thermal and hydrodynamic losses

$$
E_{1}=\frac{v_{a 0}}{d_{2}-d_{0}}\left[\rho_{a 0} C_{a 0}\left(t_{1}-t_{0}\right)+\left(p_{1}-p_{0}\right)\right]
$$

where $E_{1}$ - specific energy consumption of filtration drying at the normal pressure and filtration drying at the high pressure, JVkg.

In the case of filtration drying under high pressure all the energy brought to the compressor is spent both on heating the drying agent and on overcoming the hydrodynamic resistance of the material layer. In addition, in the case of pressure drop between the EM and the surrounding environment positive work may carried out when the gas is expanded in the throttle from the pressure $p_{2}$ to the pressure $p_{0}$. This additional work is carried out only when there is a drop in pressure on the throttle, that is, only in the case of filtration drying under the action of high pressure.

$$
E_{2}=\frac{p_{0}}{\left(d_{2}-d_{0}\right)(\gamma-1)}\left\{v_{a 0} \cdot \gamma\left[\left(\frac{p_{1}}{p_{0}}\right)^{\frac{\gamma-1}{\gamma}}-1\right]-v_{a 2}\left(\frac{p_{2}}{p_{0}}\right)^{\frac{1}{\gamma}}\left[1-\left(\frac{p_{0}}{p_{2}}\right)^{\frac{\gamma-1}{\gamma}}\right]\right\}
$$

where $E_{2}$ - specific energy consumption of filtration drying at the normal pressure and filtration drying at the high pressure, JVkg;

$d_{0}, d_{2}$ - moisture content of the air at the inlet and outlet of eveporation module, $(\mathrm{kg}$ steam $) /(\mathrm{kg}$ dry air);

$\rho_{a 0}$ - air density, $\mathrm{kg} / \mathrm{M}^{3}$;

$v_{a 0}, v_{a 2}$ - specific volume of air at the inlet and outlet of eveporation module, $\mathrm{m}^{3} / \mathrm{kg}$;

$C_{a 0}$ - specific heat of air, $\mathrm{J} /(\mathrm{kg} \cdot \mathrm{K})$;

$p_{1}, p_{2}$ - pressure at the inlet and outlet of eveporation module, $\mathrm{Pa}$; 
The calculations were carried out in Mathcad. Standard data of the pressure of saturated steam were used [4]. In calculations of specific energy consumption, constant parameters of the ambient air were used: $t_{0}=20{ }^{\circ} \mathrm{C} ; d_{0}=0,01 \mathrm{~kg} / \mathrm{kg}, p_{0}=101 \mathrm{kPa}$. The parameters of the drying agent at the outlet of the dryer were calculated in the conditions of the isoenthalipic drying process (absence of heat losses inside the dryer) under the conditions of the given relative humidity at the outlet of the dryer $\left(\varphi_{2}=0.6-1.0\right)$ and given pressure $p_{2}$.

The simulation results are listed below. In Fig. 1 a comparison of specific energy consumption in two processes of filtration drying are shown for a typical temperature range of the drying agent $40-160{ }^{\circ} \mathrm{C}$, which corresponds to compression pressures in a compressor of $0.11-0.4 \mathrm{MPa}$. In calculations, the hydrodynamic resistance of the layer was assumed to $5 \mathrm{kPa}$, which corresponds to the usual thickness of the layer $50-100 \mathrm{~mm}$ for filtration drying at normal pressure.

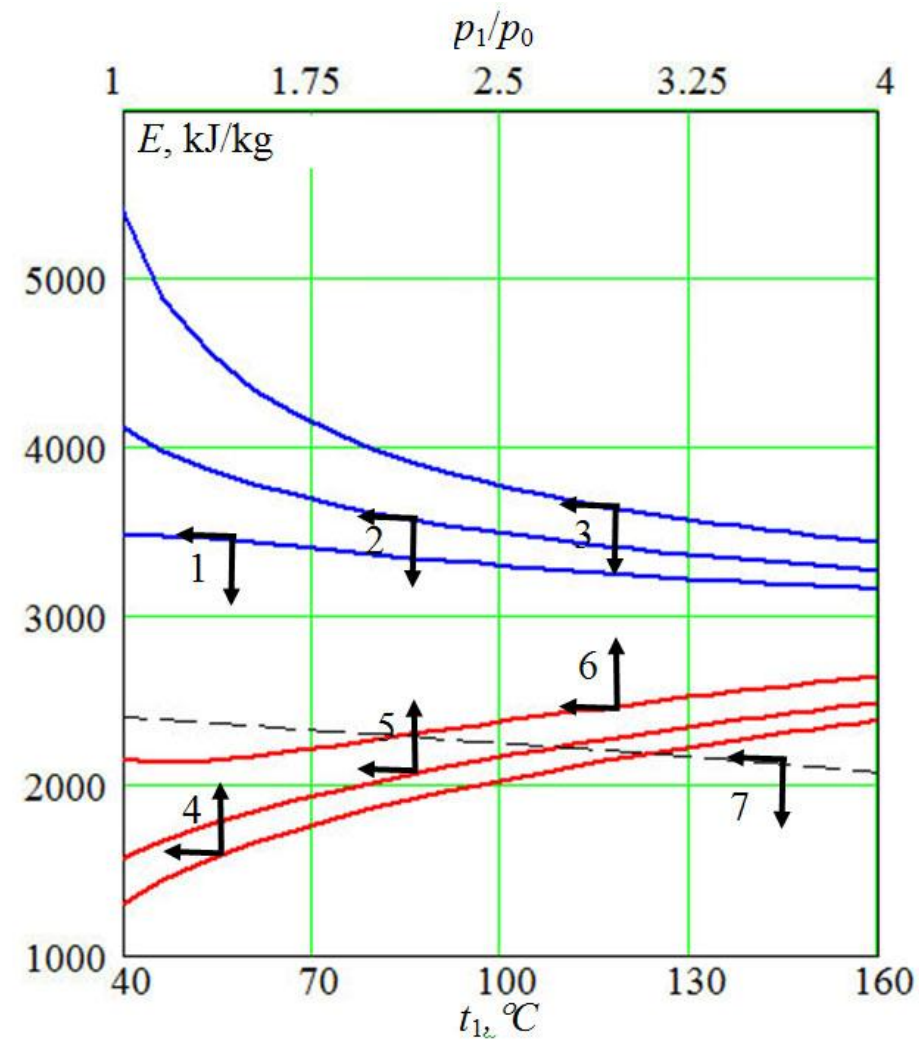

Fig.1. Specific energy consumption for two methods of filtration drying with constant hydrodynamic resistance $\Delta p=5 \mathrm{kPa}$ and different outlet air humidity:

filtration drying at the normal pressure: $1-\varphi_{2}=1 ; 2-\varphi_{2}=0,8 ; 3-\varphi_{2}=0,6$;

filtration drying at the high pressure: $4-\varphi_{2}=1 ; 5-\varphi_{2}=0,8 ; 6-\varphi_{2}=0,6$;

7 - specific heat of water vaporization.

From the above graphs, it follows that the specific energy consumption for filtration drying at normal pressure decreases with increasing temperature and for filtration drying at high pressure increases with increasing pressure (temperature). This is due to the fact that with increasing temperature of the drying agent, its absorption capacity $\left(d_{2}-d_{0}\right)$ is greater under normal atmospheric pressure than in the case of high pressure. Reducing the degree of saturation of the drying agent at the outlet of the dryer increases the energy consumption proportionally. It 
is which is quite understandable, since the specific energy consumption is inversely proportional to the difference in moisture content at the outlet and inlet of the dryer $\left(d_{2}-d_{0}\right)$.

For a constant hydrodynamic resistance of a filtration layer at $5 \mathrm{kPa}$, the specific energy consumption for filtration drying at normal pressure is $3200-5400 \mathrm{~kJ} / \mathrm{kg}$ (curves 1 - 3), whereas for filtration drying at the high pressure $1400-2700 \mathrm{~kJ} / \mathrm{kg}$ (curves $4-6$ ), that is, in a certain range of temperatures (pressures) even less than the specific heat of water vaporization. This is explained by the well-known fact that the energy conversion factor in heat pumps, where the useful work of the cycle is equal to the difference between work of the compression and expansion of the gas, is also greater than one unit. In the case of filtration drying under high pressure, this is explained by the fact that the expansion of the drying agent is spent on removing free water in a liquid state. The amount of that free water is difficult to determine, but it is well known from the experience of filtration drying that it is removed and even more so the greater the pressure difference applied to the product layer.

As calculations shows, with the increase of the hydrodynamic resistance of the layer, the energy consumption of the drying process increases for both method of drying under normal pressure and drying at a high pressure. But increasing the pressure allows you to dry a larger layer of material compared to filtration drying at normal pressure. Accordingly, this allows a proportional increase the length of the drying chamber and significantly simplifies the design of the dryer of continuous action, using a cylindrical section of the chamber with a large length to diameter ratio.

As shown by the modeling of the dependence of specific energy consumption on the compression ratio for filtration drying at high pressure there is a minimum energy consumption for a certain hydrodynamic resistance and drying temperature. This is explained by the fact that on the one hand, with the increase in the pressure of injection at a constant hydrodynamic resistance, the expansion of the gas at the outlet of the dryer increases, which is spent on squeezing the moister, on the other hand, with the increase of the pressure of injection, the absorption capacity of the drying agent decreases in comparison with the normal pressure.

\section{Conclusion}

A theoretical comparison of energy efficiency of the filtration drying process under the influence of high pressure and filtration drying at normal pressure is carried out.

It is shown for filtration drying at high pressure, the specific energy consumption is $1.5-2$ times less than in the filtration drying at normal pressure, and under certain conditions may be lower than the latent heat of evaporation of water.

\section{References}

[1] T. Kudra, "Energy aspects in drying" Drying Technology, vol. 22, no. 5, pp. 917-932, 2004

[2] V. Potapov, O. Gritsenko, "Kinetics of drying of moist material in the heat-and-mass transfer module under high pressure", "Industrial Technology and Engineering”, no. 2(07), pp. $5-9,2013$.

[3] Xiaoyan Jia Jinyue Yan, "Saturated thermodynamic properties for the air-water system at elevated temperature and pressure", Chemical Engineering Science, vol/ 58, no.22, November, pp. 5069-5077, 2003.

[4] Principles of heating ventilating and air conditioning / ASHRAE 1791 Tullie Circle, N.E. Atlanta, GA 30329, 585 p, 2013. 